\title{
Management of non-vital anterior teeth with open apex: A report of two cases
}

\author{
Beliz Özel, ${ }^{1}$ (1) Raif Erisen² \\ 'Department of Endodontics, Yeditepe University Faculty of Dentistry, Istanbul, Turkey \\ ${ }^{2}$ Department of Endodontics, Istanbul University Faculty of Dentistry, Istanbul, Turkey
}

\begin{abstract}
Treatment of teeth with open apex requires careful handling and diligence in clinical practice. Prognosis of endodontic treatment in such cases is directly related to the quality of apical obturation. Previously, a calcified barrier using calcium hydroxide treatment was recommended as an approach for these cases however due to various drawback of this method, current management approach suggests apexification through an apical plug at the apical segment.This report describes two cases of apexification of upper left incisor using mineral trioxide aggregate plug. After two year follow up, both teeth are clinically and radiographically asypmtomatic and the healing of the apical area is visible.
\end{abstract}

Keywords: Apexification; mineral trioxide aggregate; upper incisors.

$\mathrm{T}$ The endodontic treatment of teeth with open apex can be a challenge in daily practice. The apical anatomy of these teeth is characterized by greater width at the apical portion, absence of apical constriction and thin dentinal walls. Endodontic treatment of these teeth requires complete elimination of bacteria from the root canal and prevention of re-infection canal space. However, difficulties in establishing the working length (WL ${ }^{[1]}$ and extrusion of irrigation or obturation materials ${ }^{[2]}$ is possible during treatment. In order to allow the condensation of the root filling material and to promote an adequate apical seal, it is necessary to create an apical barrier. ${ }^{[3]}$

Apexification is a treatment option that is done with the aim of apical repair by formation of hard tissue barrier through apex. Conventionally, a calcified barrier is inducted using a calcium hydroxide $(\mathrm{CaOH} 2)$ mixture. ${ }^{[4]} \mathrm{Com}-$ plete formation of the calcified apical barrier is usually lasts long, requiring 6 to 24 months of treatment time. ${ }^{[5]} \mathrm{Al}-$ though opposite has been reported by Chala et al ${ }^{[6]}$ duration of this method has several drawbacks such as the risk of tooth fracture due to prolonged use of $\mathrm{CaOH} 2^{[7]}$ with re-infection of the root canal ${ }^{[8]}$ or difficulties in patient recall. Considering all these negative factors, single-visit apexification is suggested for the management of teeth with open apex. ${ }^{[9]}$

Mineral trioxide aggregate (MTA) was described as an alternative to traditional apexification treatment ${ }^{[10]}$ which incorporates the application of the material in the apical third of the canal to create an apical barrier. MTA is a biomaterial with excellent biocompability and superior sealing abilities even in the presence of moisture.

This report describes two cases of apexification in teeth with open apex managed with apical barrier technique.

Correspondence: Dr. Beliz Özel. Yeditepe Üniversitesi Diş Hekimliği Fakültesi,

Endodonti Anabilim Dalı, İstanbul, Turkey.

Tel: +90 536 - 2986170 e-mail: beliz.ozel@yeditepe.edu.tr

Submitted: May 16, 2020 Accepted: November 20, 2020 


\section{Case report}

Case 1-An 17 year old female patient ongoing orthodontic treatment was referred to Istanbul University Department of Endodontics. Clinical investigation revealed a slight discoloration on maxillary left incisor. Palpation and percussion was negative at the related area. Mobility and periodontal probing was within physiological limits. Radiographic examination showed an incomplete root formation along with a periapical lesion located lateral to the apex for tooth \#21 and (Fig. la). Pulp vitality with cold test (Endo-Frost, Roeko, Langenau, Germany) and electric pulp testing (Digitest II, Parkell Inc), gave a negative response which was suggestive of pulp necrosis. Considering the width of the apex, an apical plug was decided as the treatment plan. Patient was informed with the treatment plan and a consent form was obtained.

In the first session, coronal access was prepared with a round burr followed by rubber-dam placement for isolation. The WL was estimated by periapical radiography using a \#90 K-file. Cleaning and shaping was done with crown-down instrumentation together with $2.5 \% \mathrm{NaOCl}$ irrigation (PPH Cerkamed, Poland) and continuous aspiration to avoid any accidental extrusion of the solution.

Then, the canal was dried with sterile paper points and filled with a mixture of $\mathrm{CaOH} 2$ powder (Sultan, USA) and saline and the tooth was temporarily restored. One week later, the intracanal medicament was removed and canal was irrigated with $2.5 \% \mathrm{NaOCl}$ solution. The canal was dried with sterile paper points. MTA (Angelus, Londrina, Brazil) was mixed according to manufacturer's instructions. The mixture was applied inside the canal using MTA gun and positioning of the material was checked with radiography. Using hand pluggers (Queen, Hungary), 4-mm thick MTA plug was applied gently and packed into the apical segment followed by a confirmation radiography (Fig. 1b). A moistened cotton pellet was applied over the canal orifice and the tooth was temporarily restored. Next day, the setting of the plug was checked with an MTA plugger \#4 through a gentle pecking motion. and the rest of the canal was obturated with gutta percha (MetaBiomed, Korea) and a resin based sealer (Adseal, MetaBiomed, Korea) using lateral condensation (Fig. lc). Tooth was restored with composite (3M Filtek, 3M, USA) following root canal obturation. Orthodontic treatment was reassigned the following week.

Two year radiographic control showed that the periapical lesion at the apex was no longer present (Fig. ld). Tooth was clinically and radiographically asymptomatic.

Case 2 - A 15 year old female patient was referred to Istanbul University Department of Endodontics with the complaint of a crack on upper anterior region with the history of trauma 2 years prior to the time of reporting. Clinical examination showed a fracture on tooth \#21. The tooth was not tender to palpation or percussion testing. Mobility and periodontal probing was within physiological limits. Radiographic examination revealed an immature apex (Fig. 2a). Tooth was not responsive to cold and electrical pulp testing. The treatment plan included apexification with MTA apical plug. An informed consent was taken from the patient and his parents.

Coronal access was prepared with a round burr and caries was removed. The canal was easily located and WL was determined through radiography. Gentle circumferential filing used to remove necrosed pulp. Copious irrigation with $2.5 \% \mathrm{NaOCl}$ was done along with continuous aspiration. The canal was dried with sterile paper points and a mixture of $\mathrm{CaOH} 2$ powder with saline was placed inside. The tooth was temporarily restored and patient reappointed to next week.

Next visit, $\mathrm{CaOH} 2$ was removed. Shaping and irrigation protocol was followed as described above. The canal
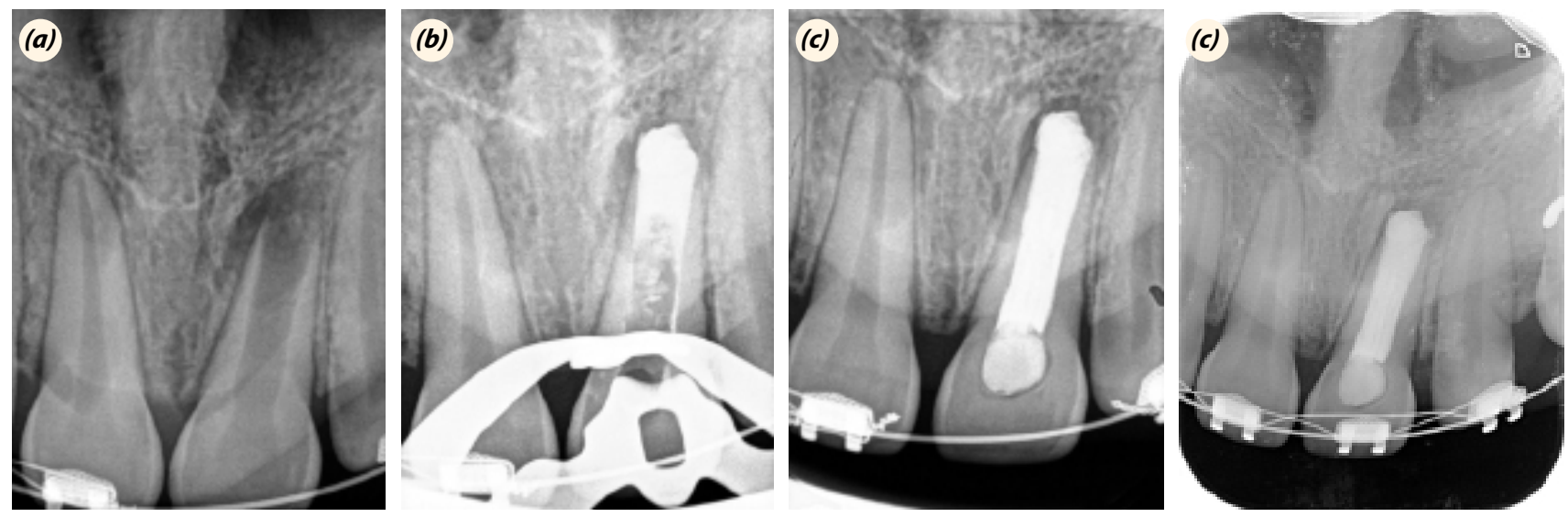

Fig. 1. (a) Preoperative radiography; (b) Induction of apical plug; (c) Canal obturation; (d) 2 year follow up. 

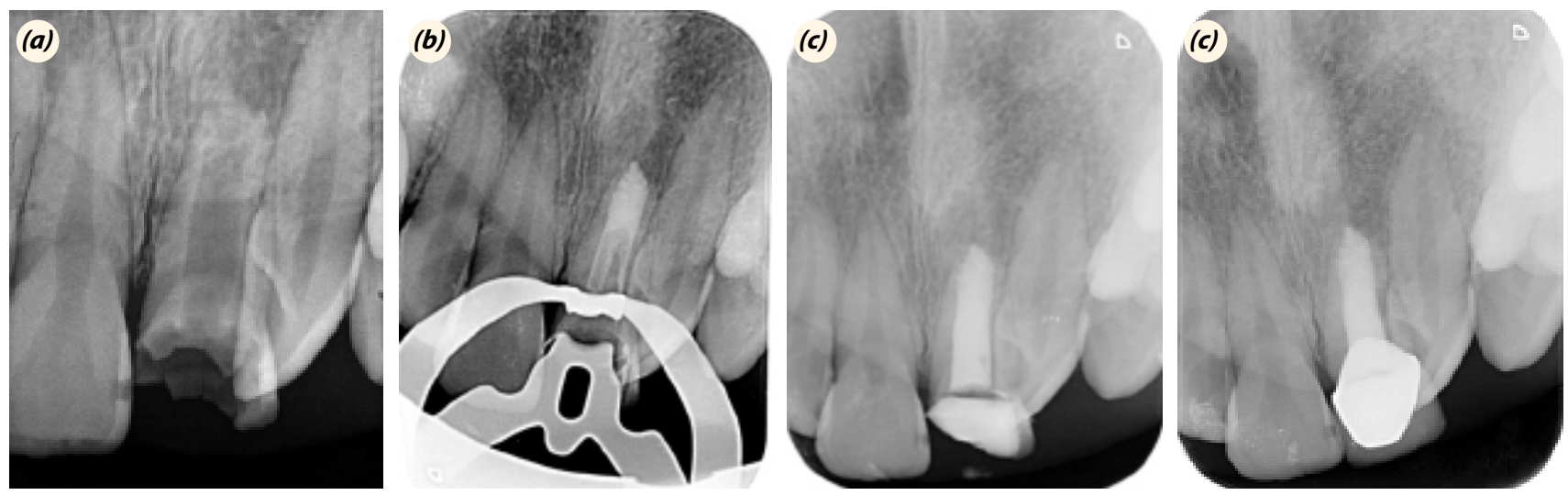

Fig. 2. (a) Preoperative radiography; (b) Apical plug with MTA; (c) Canal obturation; (d) 2 year follow up.

was dried and MTA (Angleus, Londrina, Brazil) mixed according to manufacturer's instructions was placed inside using hand pluggers. A radiographic image was taken to correct the positioning of the material. 4-mm thick MTA packed into the apical segment and confirmation radiography was taken (Fig. 2b). A moistened cotton pellet was placed at the orifice and patient was rescheduled. Next day, the hardness of the plug was ensured and the rest of the canal was sealed with lateral condensation using GuttaFlow (Roeko, Langenau, Germany) as sealer (Fig. 2c). Patient was referred to the prosthetic department for a crown restoration.

The tooth was clinically asymptomatic and functioning normally after two years. Follow-up radiography showed healing of the apical area (Fig. 2d).

\section{Discussion}

Formerly, induction of a calcified barrier using long-term $\mathrm{CaOH} 2$ medication was the most common procedure to achieve a biological seal in teeth with incomplete apical formation. ${ }^{[11]}$ Although, the technique showed clinical success, it had several disadvantages including; prolonged time period ${ }^{[12]}$ which requires patient's compliance, possibility of re-infection due to temporary sealing ${ }^{[13]}$ or tooth fracture during or after the treatment. ${ }^{[14]}$ To eliminate these risks, several studies have proposed one-visit apexification ${ }^{[7,15]}$ by placing MTA which has proven to be a suitable alternative due to its favourable physiochemical properties, biocompability ${ }^{[16]}$ and high clinical success ${ }^{[3,17]}$ Following the procedure, obturation of the canal and placement of a coronal restoration is possible. ${ }^{[18]}$ Hence, for the cases described here, an apical plug obturation was the best approach since both needed an immediate restoration.

In this report, the rationale of using an intracanal medicament prior to final obturation was primarily to limit the bacterial count since various combinations of bacte- ria are found in root canal system of necrotic teeth. ${ }^{[19]}$ $\mathrm{CaOH} 2$ has the ability to provide an antibacterial environment thus, facilitate the decontamination of the pulp cavity. ${ }^{[20]}$ Additionally, with its high $\mathrm{pH}$, the prior use of $\mathrm{CaOH} 2$ dressings becomes necessary to create favourable conditions for MTA setting and improve its properties. ${ }^{[21]}$

Treatment outcome is an important part of evidence based practice. ${ }^{[22]}$ Previously, case reports have been published about the biological apical closure appearing after the filling of the root canal. An in-vivo study on $\operatorname{dogs}{ }^{[3]}$ reported formation of apical calcified barrier in all teeth treated with an MTA plug. Similarly, in a case-control study of 50 patients ${ }^{[17]}$ apexification with MTA showed $83 \%$ success rate, emphasizing the predictability and prognosis of the treatment.

However, the success of the treatment is directly related to the diameter of the foramen or sealing ability and correct adaptation of used material. Adel et al. ${ }^{[23]}$ pointed out that an increased diameter of apical foramen or reduction of apical plug thickness significantly increases the apical microleakage of barriers. In an dye leakage study comparing different depths of MTA, 4-mm thick material showed signifcantly more effectiveness ${ }^{[24]}$ which was applied to the cases present in this report.

In present report, MTA was applied using hand pluggers for a controlled adaptation of the material. To achieve a good seal and retention during orthograd placement of MTA in teeth with open apices, delivery technique could be improved. ${ }^{[25]}$ However, a leakage study comparing various insertion techniques showed similar sealing abilities when MTA was placed with pluggers, paper-points or ultrasonic tips. ${ }^{[26]}$

As described in the reported cases, the use of MTA demonstrated clinical and radiographic success at followup controls. An apical plug can be a treatment choice for management of teeth with incomplete root formation in need of an immediate restoration. 
Conflict of interest: None declared.

Authorship contributions: Concept: B.Ö., R.E.; Design: B.Ö.; Supervisionः R.E.; Materials: B.Ö.; Data: B.Ö.; Analysis: B.Ö.; Literature search: B.Ö.; Writing: B.Ö.; Critical revision: R.E.

\section{References}

1. de Jesus Soares A, Yuri Nagata J, Casarin RC, Flávio Affonso de Almeida J, Gomes BP, Augusto Zaia A, et al. Apexification with a new intra-canal medicament: a multidisciplinary case report. Iran Endod J 2012;7:165-70.

2. Trope M, Chivian N, Sigurdsson A. The role of endodontics after dental traumatic injuries. In: Cohen $\mathrm{SH}$, editor. Pathways of the pulp. 10 ed. St Louis: Mosby; 2006. p. 610-49.

3. Felippe WT, Felippe MC, Rocha MJ. The effect of mineral trioxide aggregate on the apexification and periapical healing of teeth with incomplete root formation. Int Endod J 2006;39:2-9.

4. Nair PN. Pathogenesis of apical periodontitis and the causes of endodontic failures. Crit Rev Oral Biol Med 2004; $15: 348-81$.

5. Al Ansary MA, Day PF, Duggal MS, Brunton PA. Interventions for treating traumatized necrotic immature permanent anterior teeth: inducing a calcific barrier $\&$ root strengthening. Dent Traumatol 2009;25:367-79.

6. Chala S, Abouqal R, Rida S. Apexification of immature teeth with calcium hydroxide or mineral trioxide aggregate: systematic review and meta-analysis. Oral Surg Oral Med Oral Pathol Oral Radiol Endod 2011;112:e36-42.

7. Andreasen JO, Farik B, Munksgaard EC. Long-term calcium hydroxide as a root canal dressing may increase risk of root fracture. Dent Traumatol 2002;18:134-7.

8. Maroto M, Barbería E, Planells P, Vera V. Treatment of a non-vital immature incisor with mineral trioxide aggregate (MTA). Dent Traumatol 2003;19:165-9.

9. Khalilak Z, Vali T, Danesh F, Vatanpour M. The Effect of One-Step or Two-Step MTA Plug and Tooth Apical Width on Coronal Leakage in Open Apex Teeth. Iran En$\operatorname{dod} \mathrm{J} 2012 ; 7: 10-4$.

10. Torabinejad M, Chivian N. Clinical applications of mineral trioxide aggregate. J Endod 1999;25:197-205.

11. Corbella S, Ferrara G, El Kabbaney A, Taschieri S. Apexification, apexogenesis and regenerative endodontic procedures: a review of the literature. Minerva Stomatol 2014;63:375-89.

12. Rafter M. Apexification: a review. Dent Traumatol
2005;21:1-8.

13. Torabinejad M, Rastegar AF, Kettering JD, Pitt Ford TR. Bacterial leakage of mineral trioxide aggregate as a rootend filling material.J Endod 1995;21:109-12.

14. Kahler SL, Shetty S, Andreasen FM, Kahler B. The Effect of Long-term Dressing with Calcium Hydroxide on the Fracture Susceptibility of Teeth.J Endod 2018;44:464-69.

15. Witherspoon DE, Ham K. One-visit apexification: technique for inducing root-end barrier formation in apical closures. Pract Proced Aesthet Dent 2001;13:455-60

16. Torabinejad M, Pitt Ford TR. Root end filling materials: a review. Endod Dent Traumatol 1996;12:161-78.

17. Simon S, Rilliard F, Berdal A, Machtou P. The use of mineral trioxide aggregate in one-visit apexification treatment: a prospective study. Int Endod J 2007;40:186-97.

18. Steinig TH, Regan JD, Gutmann JL. The use and predictable placement of Mineral Trioxide Aggregate in one-visit apexification cases. Aust Endod J 2003;29:34-42.

19. Sundqvist GK, Eckerbom MI, Larsson AP, Sjögren UT. Capacity of anaerobic bacteria from necrotic dental pulps to induce purulent infections. Infect Immun 1979;25:685-93.

20. Mohammadi Z, Dummer PM. Properties and applications of calcium hydroxide in endodontics and dental traumatology. Int Endod J 2011;44:697-730.

21. Saghiri MA, Lotfi M, Saghiri AM, Vosoughhosseini S, Aeinehchi M, Ranjkesh B. Scanning electron micrograph and surface hardness of mineral trioxide aggregate in the presence of alkaline $\mathrm{pH}$. J Endod 2009;35:706-10.

22. Peak JD, Hayes SJ, Bryant ST, Dummer PM. The outcome of root canal treatment. A retrospective study within the armed forces (Royal Air Force). Br Dent J 2001;190:140-4.

23. Adel M, Nima MM, Shivaie Kojoori S, Norooz Oliaie H, Naghavi N, Asgary S. Comparison of endodontic biomaterials as apical barriers in simulated open apices. ISRN Dent 2012;2012:359873.

24. Valois CR, Costa ED Jr. Influence of the thickness of mineral trioxide aggregate on sealing ability of root-end fillings in vitro. Oral Surg Oral Med Oral Pathol Oral Radiol En$\operatorname{dod} 2004 ; 97: 108-11$.

25. Hachmeister DR, Schindler WG, Walker WA 3rd, Thomas DD. The sealing ability and retention characteristics of mineral trioxide aggregate in a model of apexification.J En$\operatorname{dod} 2002 ; 28: 386-90$.

26. Alhaddad Alhamoui F, Steffen H, Splieth CH. The sealing ability of ProRoot MTA when placed as an apical barrier using three different techniques: an in-vitro apexification model. Quintessence Int 2014;45:821-7. 